\title{
GROUNDING, ESSENCE, AND IDENTITY
}

\author{
Fabrice Correia \\ University of Neuchâtel \\ Alexander Skiles* \\ New York University
}

\begin{abstract}
Recent metaphysics has turned its focus to two notions that are-as well as having a common Aristotelian pedigree-widely thought to be intimately related: grounding and essence. Yet how, exactly, the two are related remains opaque. We develop a unified and uniform account of grounding and essence, one which understands them both in terms of a generalized notion of identity examined in recent work by Fabrice Correia, Cian Dorr, Agustín Rayo, and others. We argue that the account comports with antecedently plausible principles governing grounding, essence, and identity taken individually, and illuminates how the three interact. We also argue that the account compares favorably to an alternative unification of grounding and essence recently proposed by Kit Fine.
\end{abstract}

Recent metaphysics has turned its focus to two notions that are-as well as having a common Aristotelian pedigree-widely thought to be intimately related: grounding (when some phenomenon non-causally 'derives' from another) and essence (when some phenomenon is in the 'nature' of another). However, how they're related remains quite opaque. ${ }^{1}$ We aim to clarify their link by proposing a unified and uniform account of both notions that analyzes them in terms of a third: what we call, following Linnebo (2014), generalized identity. Along with the intrinsic desirability of accounting for either notion alone (which has proven elusive), our proposal illuminates how the two interact by means of a single, relatively wellbehaved conceptual tool.

What do we mean by "generalized" identity? Objectual identities (e.g. "Hesperus is Phosphorus") are familiar, and display a canonical form: an identity-indicating

\footnotetext{
* This article is the product of full and equal collaboration between its authors; the order of authorship is alphabetical.

1 How grounding and essence interact is explicitly taken up in Audi $(2012 ; 2015)$, Carnino (2014), Correia (2005; 2013), Dasgupta (2014; 2016), Fine (2012; 2015), Guigon (forthcoming), Greenberg (2014), Kment (2014), Koslicki (2012; 2015), Rosen (2012; 2015), Skiles (2015), Trogdon (2015), and Zylstra (forthcoming).
} 
phrase like "is" gets treated as a relational predicate, flanked by two designators for entities. Despite the unfamiliar name, generalized identities are no less philosophically commonplace. Consider:

(1) For a thing to be a bachelor is for it to be an unmarried adult male.

(2) For a thing to know a proposition is for it to truly, justifiably believe that proposition.

(3) For the Atlantic Ocean to be filled with water is for it to be filled with $\mathrm{H}_{2} \mathrm{O}$ molecules. ${ }^{2}$

These statements are clearly analogous to objectual identities: one could readily substitute in phrases like "is the same as" or "is no different than", cancelling any implication that the "is" at issue is one of predication or existence. Yet they deviate in logical form, at least at the grammatical surface. "For the Atlantic Ocean to be filled with water" in (3), e.g., doesn't seem to be in the designating business, and the truth of (3) doesn't seem to hinge upon its being so. Surely we should believe (3), a mundane chemical-geological truth, even if metaphysical inquiry reveals no 'fact-shaped' entities with just the right individuation conditions (Cameron 2014, p. 431; Dorr 2016, pp. 40-1; Rayo 2013, pp. 66-8). And certain examples patently resist a straightforward objectual reading. Consider:

(4) For a thing to be a non-self-instantiator is for it to be a property that doesn't instantiate itself.

Familiar Russellian reasoning demonstrates that there is no such property being a non-self-instantiator, raising obvious trouble for the view that (4) expresses an identity involving it (Correia 2006, pp. 761-2; Dorr 2016, p. 40). ${ }^{3}$

2 For additional examples of the idiom, see Correia (2010, pp. 256-7), Dorr (2016, p. 39), King (1998, p. 156), Kment (2014, p. 153), Koslicki (2012, pp. 197-203), and Rayo (2013, p. 3).

3 Those who, like us, deny that that generalized identities are objectual identities in disguise might nonetheless uphold the following, more cautious principles:

(i) If the property of being $F$ and the property of being $G$ both exist, then for a thing to be $F$ is for it to be $G$ iff the property of being $F=$ the property of being $G$.

(ii) If the fact that $p$ and the fact that $q$ both exist, then for it to be the case that $p$ is for it to be the case that $q$ iff the fact that $p=$ the fact that $q$. 
Although not themselves objectual identities, recent studies have shed light on the nature, logic, and epistemology of generalized identities by extending principles widely thought to govern objectual identity, to cover the "is" of statements like (1)-(4). ${ }^{4} \mathrm{~A}$ common refrain-a crucial one for our purposes-is that generalized identity needn't only be full, as in (1)-(4). It can also be partial, as when one says that for a proposition to be known is in part for it to be true (but not in full, since it must also be justifiably believed). Current work focuses on partial generalized identities of the conjunctive variety, like the one mentioned. Yet it also comes in a disjunctive variety, and both are analyzable in terms of the full. Distilled to its core, our account unifies grounding and essence by analyzing essence in terms of the conjunctive variety, and grounding in terms of the disjunctive variety.

Here's our plan. In section 1, we further introduce the notion of generalized identity. In sections 2 and 3, we develop accounts of essence and grounding in terms of generalized identity, respectively. In section 4 , we argue that the framework compares favorably to a unification of grounding and essence recently proposed by Fine (2015). Finally, in section 5 we conclude with several open questions about generalized identity to guide future research on grounding and essence.

\section{Generalized identity}

Our take on generalized identity builds on-yet in certain key respects deviates from—frameworks put forward by Correia (2010; 2016), Rayo (2013), and Dorr (2016). Space limitations preclude a full development and comparison, so we concentrate only on those elements of the resulting theory most relevant for later purposes.

\footnotetext{
We (the authors) disagree over these principles, due to certain background disagreements regarding the nature and existence of properties and facts. Fortunately, for present purposes we can let these disagreements lie: neither (i) nor (ii) is assumed in the course of what follows. (But see the end of section 3.2 for some remarks on views which endorse (i) or (ii).)

4 See Correia (2010; 2016), Dorr (2016), Linnebo (2014), and Rayo (2013). Also pertinent is the critical discussion of Rayo's distinctive theory and applications of the notion in his The Construction of Logical Space: see Cameron (2014), Eklund (2014), Greco (2015), Hofweber (2014), Russell (2014), Sider (2014) and Turner (2015), and see Rayo (2014; 2015b) for replies.
} 
Following Rayo, we express generalized identity with an operator, $\equiv$, indexed by zero or more variables, which takes two open or closed sentences and yields another. Where $p$ and $q$ are open or closed sentences,

$$
p \equiv q
$$

should be read as "For it to be the case that $p$ is for it to be the case that $q$ "; and where $F$ and $G$ are monadic predicates,

$$
F X \equiv_{X} G X
$$

should be read as "For a thing to be $F$ is for it to be $G$ ". ${ }^{5}$ More generally, a statement of the form

$$
p \equiv_{x, y, \ldots} q
$$

should be read as "For some things $x, y, \ldots$ to be such that $p$ is for them to be such that $q "{ }^{\prime}{ }^{6}$ We read such statements as not requiring that the flanking expressions be true/satisfied: for instance, it is intuitively no objection to (1) that there aren't any bachelors. For short, we read them non-factively. We call type-(5) statements factual identities, and call type-(7)-and therefore type-(6)-statements generic identities.

Although it's tempting to read "For ... is for __" statements as indicating a type of priority of one side to the other, $\equiv$ is instead to be read as what Rayo evocatively calls a "no-difference operator" (2014, pp. 518). Accordingly, we take it to behave

5 Here and elsewhere, we fudge typical use-mention conventions when no confusion should result, and allow context to sort out whether we use "identities" to refer to statements about what is identical to what vs. the identities out there in the world (so to speak).

6 Note that in such a statement, the variables $x, y, \ldots$ need not bind all free variables in $p$ and $q$ : to use an example of Dorr's (2016, p. 48), to assume otherwise precludes quantified generalized identity statement like " $\exists y\left(x\right.$ is German $\equiv_{x} x$ is from $\left.y\right)$ ", which are surely sensible. Also note that we focus on cases in which $\equiv$ binds first-order and singular variables to simplify. In fact there are examples plausibly regimented with $\equiv$ instead binding higher-order variables (as in "For it to be possible that $p$ is $p$ for there to be a spatiotemporally isolated universe in which $p$ "; cf. Lewis 1986) or plural variables (as in "For $x x$ to be countably infinite is $x_{x x}$ for $x x$ to one-one correspond to the natural numbers"); cf. Rayo (2013, p. 146) and Dorr (2016, pp. 49 ff.). Working with this broader class of generalized identities would allow us to extend our accounts of grounding and essence in correspondingly broader ways, but doing so would complicate matters too much here. 
like the familiar no-difference predicate for what we've called objectual identity (a.k.a. =). As such, we take $\equiv$ to be reflexive, symmetric, and transitive, i.e. that the following hold for any $p, q$, and $r$, and any sequence $\mathbf{v}$ of zero or more variables:

$$
\begin{array}{ll}
\text { Reflexivity: } & p \equiv_{\mathbf{v}} p \\
\text { Symmetry: } & \text { If } p \equiv_{\mathbf{v}} q \text {, then } q \equiv_{\mathbf{v}} p \\
\text { Transitivity: } & \text { If } p \equiv_{\mathbf{v}} q \text { and } q \equiv_{\mathbf{v}} r \text {, then } p \equiv_{\mathbf{v}} r
\end{array}
$$

The truth of $p \equiv_{\mathbf{v}} q$ also allows for representational differences between $p$ and $q$. Except in the trivial reflexive cases, there is a syntactic difference between them, and perhaps further differences in their semantic values or cognitive uptake (e.g. the 'guise' their contents are presented under). But such differences no more undermine a generalized identity than those between "Hesperus" and "Phosphorus" undermine the truth of "Hesperus = Phosphorus" (cf. Dorr 2016, pp. 42-6; Rayo 2013, pp. 52-4).

We also take it that some (interesting) restriction of Leibniz's Law for $\equiv$ must be correct:

\section{LL: $\quad$ If $p \equiv_{\mathrm{v}} q$ and $\Phi$, then $\Phi[q / / p]$}

where $\Phi[q / / p]$ results from sentence $\Phi$ by replacing one or more occurrences of $p$ by $q$, with the condition that no variable that is free in $p \equiv_{\mathbf{v}} q$ is bound in $\Phi$ or $\Phi[q / / p]$ (see Dorr 2016, p. 49)

We say "some restriction", because, just like its objectual counterpart, the law fails if understood unrestrictedly. Belief ascription contexts provide clear counterexamples: granted that for a thing to be a water molecule is for it to be an $\mathrm{H}_{2} \mathrm{O}$ molecule, we cannot infer that John believes that his glass is filled with $\mathrm{H}_{2} \mathrm{O}$ molecules from the assumption that he believes that his glass is filled with water molecules. Other clear examples of 'opaque' linguistic contexts are quotation contexts, and contexts like "the proposition that ... is distinct from the proposition that__" and "the concept of being ... is distinct from the concept of being __" on a sufficiently fine-grained conception of propositions and concepts, respectively (see Dorr 2016, pp. 43-46 and 53-54). Determining exactly which linguistic contexts are 
opaque for objectual identity is no easy task, and the situation is no different in the case of generalized identity. Fortunately, we won't need to provide a detailed discussion of the issue, and we trust the reader will agree with us that our applications of LL will always involve contexts that are clear candidates to be transparent (or at least not clear candidates to be opaque). ${ }^{7}$

As with objectual identity, generalized identity is tightly linked to metaphysical necessity. Specifically (and ignoring non-monadic cases):

(8) If $F x \equiv_{x} G x$ then $\square \forall x \square(F x$ iff $G x)$

(9) If $p \equiv q$, then $\square(p$ iff $q$ )

We are indeed happy to hold that the contexts “ $\square \forall x \square(F x$ iff ...)" and “ $\square(p$ iff ...)" are transparent for generalized identity, and hence to derive these principles from LL. But we reject the converses of (8) and (9):

If $\square \forall x \square(F x$ iff $G x)$, then $F x \equiv_{x} G x$

(11) If $\square(p$ iff $q)$, then $p \equiv q$

We strain to hear an intuitive reading of $\equiv$ (that treats it as a no-difference operator akin to =, anyway) that verifies all instances of (10) and (11). Given how Goodman (1955) defines "grue" and "bleen", (10) has the seemingly false consequence that to be green is to be either grue-if-observed-no-later-than-3000-A.D. or bleenif-observed-afterward (see Dorr 2016, pp. 70-1 for discussion of this example in a related context). Given the standard assumption that mathematical and logical truths hold necessarily, (11) has the seemingly false consequence that for to $2+2$ to equal 4 is for everything to be self-identical. ${ }^{8}$

7 Thanks to a referee for pressing us to clarify here. We should add that we also believe that the context “... $\equiv_{\mathbf{v}} \ldots$ " is an archetypical example of a transparent context (cf. Dorr ibid.), and hence we are happy to derive the symmetry and transitivity of $\equiv$ from its reflexivity using LL, in the same way that the symmetry and transitivity of = is standardly derived from its reflexivity using Leibniz's Law for $=$.

8 For another counterexample, see Cameron (2014, p. 431). Though Rayo (2013) endorses (10) and (11), we lack the space to evaluate his motivation and defense of these principles here, which relies on some highly contentious stances that Rayo takes about e.g. the nature of modality, which those who theorize with generalized identity per se needn't adopt (cf. Linnebo 2014, fn. 26). 
Here's one advantage of treating (8)-(11) as logically valid, though: a logic for $\equiv$ follows from one's preferred modal logic for $\square$ automatically. Since we reject (10) and (11), things aren't so easy for us. Luckily, we can focus on a narrower question where progress has been made: which truths of type $p \equiv_{\mathrm{v}} q$ hold as a matter of the logical form of $p$ and $q$ ?

Correia (2016) provides what we take to be a correct partial answer for the case of factual identity. ${ }^{9}$ Start with a standard propositional language with negation $(\neg)$, conjunction $(\wedge)$, and disjunction $(\vee)$ left primitive, and define the formulas as usual. Correia argues from semantic considerations that the logical truths of the form $p \equiv q$, where $p$ and $q$ are formulas in the language defined, are just the theorems of the system we call "GI", defined by the following axioms and rules (structurally analogous principles are listed horizontally):

\section{Axioms of GI:}

A1.

$$
p \equiv \neg \neg p
$$

$\mathrm{A} 2$

$$
p \equiv p \wedge p
$$

A3. $p \equiv p \vee p$

A4. $\quad p \wedge q \equiv q \wedge p$

A5. $\quad p \vee q \equiv q \vee p$

A6. $\quad p \wedge(q \wedge r) \equiv(p \wedge q) \wedge r$

A7. $\quad p \vee(q \vee r) \equiv(p \vee q) \vee r$

A8. $\quad \neg(p \wedge q) \equiv \neg p \vee \neg q$

A9. $\neg(p \vee q) \equiv \neg p \wedge \neg q$

A10. $p \wedge(q \vee r) \equiv(p \wedge q) \vee(p \wedge r)$

\section{Rules of GI:}

R1. $p \equiv q / q \equiv p$

R2. $p \equiv q, q \equiv r / p \equiv r$

R3. $p \equiv q / p \wedge r \equiv q \wedge r$

R4. $\quad p \equiv q / p \vee r \equiv q \vee r$

9 We are aware that the correct logic of generalized identity remains a matter of controversy; cf. Dorr's (2016) detailed discussion in sections 6, 7 and 8 for some key points of dispute. However, we believe that our account of grounding and essence in terms of generalized identity is compatible with a range of different views about the logic of the notion. Given the popularity of the theory of structured propositions and its virtues for the purpose of semantic theorizing, it is both natural and appropriate to wonder whether this range of views includes the view that factual identities are equivalent to objectual identities between such propositions. In line with a previous remark (see fn. 3), we want to remain neutral on whether factual identities are equivalent to objectual identities between structured propositions when the latter are available. But we want to stress that for a view of that kind to be viable, it should not involve a too fine-grained conception of propositions. Similar considerations apply to theories of structured properties. 
Importantly, the dual of A10,

A11. $p \vee(q \wedge r) \equiv(p \vee q) \wedge(p \vee r)$,

isn't a theorem of GI, and a rule for negation corresponding to R3 and R4,

R5. $p \equiv q / \neg p \equiv \neg q$,

doesn't preserve theoremhood in GI. (Given A1-10 and R1-4, adding A11 turns out equivalent to adding R5: see Fine 2016, pp. 204.)

GI is neatly related to systems characterizing notions of equivalence more coarsely grained than factual identity. Adding A11 or R5 yields Angell's (1989) first-degree system for analytic equivalence (adding A11 actually yields Fine's 2016a axiomatization of that system). For another comparison, consider:
A12. $p \equiv p \wedge(p \vee q)$
A13. $p \equiv p \vee(p \wedge q)$

As Angell (1977) stresses, adding either A12 or A13 as axioms to the (1989) system-which are provably equivalent in GI, which this system contains as a fragment-yields the logic of mutual first-degree entailment of Anderson \& Belnap (1962; 1963). Adding either A14 or A15 to Anderson \& Belnap's logic makes $\equiv$ behave like classical logical equivalence:
A14. $p \equiv p \wedge(q \vee \neg q)$
A15. $p \equiv p \vee(q \wedge \neg q)$

(A14 and A15 are already equivalent in Angell's system.)

Since our main interest here are applications of generalized identity—leaving only so much space to investigate its theory—we'll make some (we think reasonable) assumptions. We assume that GI specifies which factual identities hold as a matter of the truth-functional logical form of their flanking expressions, and that R1-R4 aren't only validity- (i.e. logical truth-) preserving, but also truth-preserving. We also assume that the generic operators $\equiv_{x, y}, \ldots$ logically behave in much the same way as the factual operator $\equiv$ (which is not to say that extra principles, specific to 
these operators, are not required; see e.g. Dorr's (2016, p. 49) principle of Alphabetic Variation). Finally, we grant ourselves the resources to quantify into nonnominal positions occupied by predicational and sentential expressions, and that doing so needn't be read as covertly ranging over a domain of entities. ${ }^{10}$ Yet we won't need the full strength of all these claims in what follows. We will indicate exactly which postulates for generalized identity we take for granted and why, and why we reject certain principles validated by logics for coarser notions of equivalence.

Finally, we adopt the working hypothesis that generic and factual identity are pieces of primitive ideology. Cowling (2013) argues-convincingly, we thinkthat when determining how ideologically committed a theory is, one should count the kinds of primitive ideology it employs, not each piece individually. Though we find it intuitively natural to group $=, \equiv_{\mathbf{v}}$, and $\equiv$ together, and thus that taking the latter two as primitive is no more ideologically profligate than taking the first as primitive alone, we needn't press the case further here. ${ }^{11}$ Our primary goal is to analyze two other notions that many take as distinct kinds of primitive ideology: grounding and essence. Given that all these notions must be accounted for somehow, our account leaves one no more ideologically loaded than before: either one starts with at most four kinds (grounding and essence; objectual and non-objectual identity) and ends with at most two, or one decreases instances of primitive ideology (grounding and essence; objectual, generic, and factual identity) by at least two. ${ }^{12}$

\footnotetext{
${ }^{10}$ For defense and applications of the non-substitutional take on this apparatus that we prefer, see e.g. Dunaway (2013), Prior (1971, ch. 3), Rayo \& Yablo (2001), Williamson (2003), and Wright (2007); also cf. Dorr (2016, pp. 49-50) for discussion of these resources in the context of generalized identity.

11 There's also a more theoretical case to be made (but to reiterate, its prospects do not affect our main aim). Suppose that interanalyzability among a cluster of primitives is strong evidence they fall under the same kind (cf. Cowling 2013, p. 3900 for a somewhat similar view). Then one may reasonably argue the condition is met by analyzing the objectual " $a=b$ " with " $a$ " and " $b$ " proper names as the generic " $x$ is $a \equiv_{X} x$ is $b$ " (cf. Rayo 2013, p. 69), analyzing the generic " $p \equiv_{x, y}, \ldots$ $q$ " as the factual " $\square \forall x \forall y \ldots(p \equiv q)$ ", and analyzing the factual " $p \equiv q$ " as the generic " $x$ is such that $p$ $\equiv_{X} X$ is such that $q "$.

12 Modulo the issue of whether the higher-order quantificational resources we help ourselves to must be treated as primitive ideology as well. Our own view is that one ought to do so regardless, but lack the space to defend that view here (but see the work cited in fn. 10).
} 


\section{Essence in terms of generalized identity}

Philosophers traditionally speak of essence when speaking of the very 'nature' of some phenomenon (or 'what it is') rather than how that phenomenon 'incidentally' happens to be. Like Fine (1994) and many others, we deny that what's essential to phenomenon is merely what holds of it necessarily; and more generally, we deny that the broadly Aristotelian notion of essence at issue here is analyzable in purely modal terms (see e.g. Robertson \& Atkins 2016 for a general overview). Yet essence is said in many ways; to properly set up our account, a couple preliminaries about its varieties need introduction.

We concentrate on essentialist statements falling under three broad categories: objectual, generic, and factual (cf. Correia 2006; 2013, who uses "alethic" instead of "factual"). Examples include (12), (13), and (14) respectively:

(12) It's essential to Socrates to be a human.

(13) It's essential to being a human to be a rational animal.

(14) It's essential to Socrates's being a human that he be a rational animal.

To keep matters manageable, among the generic statements, we focus on monadic cases like (13) (the extension to relational cases is obvious), and in this section we leave aside other essentialist statements that don't fit neatly into these three classes. Importantly, in section 4 we will broaden the perspective and consider collective essentialist statements, which will allow us to highlight a pleasing symmetry between the concept of essence and the concept of grounding. ${ }^{13}$

It will also be important to distinguish between describing what such-and-such is in full vs. at least in part (cf. Dasgupta 2015, pp. 18-20). A truth of full essence must at least specify a necessary and sufficient condition for such-and-such. As it is sometimes put, such truths 'individuate' their target, and in the case of objectual

\footnotetext{
13 We concentrate on essentialist statements (in English) for sake of perspicuity and ease, though strictly speaking our concern is with whatever it is out there in the world (so to speak) these statements are equipped to report. To avoid distractions regarding how this more metaphysically loaded way of speaking is to be understood (e.g. does it require commitment to entities of some sort, or would a more deflationary approach suffice?), we prefer to speak in the first way, but one is free to translate our discussion if one wishes.
} 
essence must specify an 'individual essence' of the object in question. So understood, our use of "full" is tolerant of multiple truths of full essence: (13), for instance, might state the full essence of being a human even if it's also fully essential to being human to have a certain genetic makeup/evolutionary lineage. Truths of partial essence need only specify what's necessary for such-and-such. So while every truth of full essence is (trivially) a truth of partial essence, given that there can be humans besides Socrates, (12) is charitably read as a truth of the second sort but not the first.

Preliminaries in tow, again consider (13). We claim that (13) just is a statement of generalized identity: it truly characterizes what being human is in full (generic essence) iff this is, in fact, what being human is (generic identity). More generally (again, we stick to the monadic case):

FULL-GENERIC-ESSENCE Being $F$ is what it is to be $G$ in full iff: for a thing to be $G$ is for it to be $F$ (in symbols: $G X \equiv_{X} F X$ ).

We offer FULL-GENERIC-ESSENCE as itself a generalized identity, and use "iff:" for the sake of readability. We make no commitment, however, on whether the right-hand side of FULL-GENERIC-ESSENCE expresses what philosophers 'meant all along' when speaking of full essence (recall, generalized identity tolerates representational differences between the flanking expressions). That said, we offer it not merely as a stipulative definition of some special-purpose technical notion. After all, FULL-GENERIC-ESSENCE self-applies: its truth requires that it itself state what full essence is in full (in the tolerant sense of "full"). We take it that philosophers grasp at least some essential truths about full essence, and on this basis can grasp certain core applications of the notion about which there's widespread (albeit imperfect) agreement. We thus accept the burden of showing that FULL-GENERIC-ESSENCE comports with these core applications to a high degree (and similarly for further components of the account to come).

Statements of partial essence are, in contrast, statements of generalized identity that are partial in a certain sense: being an animal is part of what being human is 
(generic essence) iff this is, in fact, what being a human partially is (generic identity). More generally:

PARTIAL-GENERIC-ESSENCE Being $F$ is partially what it is to be $G$ iff: there is some $H$ such that for a thing to be $G$ is for it to be both $F$ and $H$ (in symbols: $G x \equiv_{x} F x \wedge H x$ ).

The relevant sense of partial identity is tied to conjunction. Suppose (13) is true; then being rational, and being an animal, are what we'll call conjunctive parts of being a human. (Talk of conjunctive parthood shouldn't be read as concerning a proper relation of part to whole, though we'll continue to talk loosely.)

Why believe that FULL/PARTIAL-GENERIC-ESSENCE are true? In part because treating them as such sheds light on how grounding and essence relate in ways illustrated later. Yet there are also considerations speaking favor of them in their own right.

One is that philosophers routinely characterize essence as if it's intimately linked to non-objectual identity, in at least two ways. First, "To be $F$..." statements are often introduced as generic essence statements, then assumed to at least entail an objectual identity involving the property being $F$ (see e.g. King 1998, p. 157 and fn. 26; Kment 2014, p. 153-5; Koslicki 2012, pp. 197-201; Wedgwood 2007, pp. 1389). But this runs into difficulties like those we raised at the onset. What is it to be a non-self-instantiator? It's, in part, to be something that doesn't instantiate itself. Yet there's no property being a non-self-instantiator (cf. Correia 2006, pp. 760-3 for this and further arguments). Treating essence as also linked to non-objectual identity via PARTIAL-GENERIC-ESSENCE evades the problem while still linking "To be $F$..." to statements of identity.

Second, when discussing objectual essence, philosophers routinely use phrases like "a thing's essence" interchangeably with phrases like "the identity of a thing" (see e.g. Fine 1994, p. 3; Lowe 2008, p. 37; Shalkowski 2008, p. 37). However, an objectual reading renders this link mysterious. To speak of a thing's identity in the sense of essence isn't merely to report the triviality that it's self-identical (Lowe ibid.), nor that there are non-trivial necessary and sufficient conditions for being identical to it: only some such conditions describe what's essential to the thing at 
issue (as straightforward modifications of Fine's famous examples have taught us: 1994, pp. 4-5). Essence and identity link together perfectly, though, if one brings in non-objectual notions of both. Following Correia (2006, pp. 764-5) we account for objectual essence in terms of generic essence:

FULL-OBJECTUAL-ESSENCE Being $F$ is what $x$ is in full iff: being $F$ is what it is to be $x$.

PARTIAL-OBJECTUAL-ESSENCE Being $F$ is what $x$ is in part iff: being $F$ is part of what it is to be $x$.

PARTIAL-OBJECTUAL-ESSENCE and PARTIAL-GENERIC-ESSENCE together yield an account of partial objectual essence in terms of generalized identity: a statement like (12) truly describes part of what Socrates is (objectual essence) just in case it truly describes what being Socrates partially is (generic identity). And similarly for FULLGENERIC-ESSENCE and FULL-OBJECTUAL-ESSENCE.

The account can also be extended to factual essence:

FULL-FACTUAL-ESSENCE

PARTIAL-FACTUAL-ESSENCE
Its being the case that $p$ is what it is for it to be the case that $q$ in full iff: for it to be the case that $q$ is for it to be the case that $p$ (in symbols: $q \equiv p$ ).

Its being the case that $p$ is in part what it is for it to be the case that $q$ iff: there is some $r$ such that for a thing to be $q$ is for it to be the case that both $p$ and $r$ (in symbols: $q \equiv p \wedge r$ ).

We've noted a few core applications of essence our account accommodates, but the case for extensional adequacy extends well beyond these (we continue to focus on monadic generic essence, but what we say below generalizes).

To illustrate, compare our account with one proposed by Rayo (2013, pp. 122-3), which takes roughly the form of the above, yet takes mutual necessitation to be necessary and sufficient for generalized identity. Since being $F$ is necessary for being a particular thing, $a$, iff being $a$ mutually necessitates being $a$ and being $F$, Rayo's account entails that it is essential to $a$ that it is $F$ iff being $F$ is necessary for being $a$. Rayo's account is thus ill-suited to capture the broadly Aristotelian notion 
of objectual essence we aim to capture (as, again, Fine's famous cases have taught us). ${ }^{14}$ Moreover, if mutual necessitation sufficed for generic identity, the following would universally hold:

(15) $F X \equiv_{X} F X \wedge(F X \vee G X)$

(16) $F X \equiv_{X} F X \wedge(G X \vee \neg G X)$

These are generic versions of principles A12 and A14, respectively, mentioned in section 1. We denied A12 and A14 the status of logical validities, and do the same with (15) and (16): clearly, to be a number isn't the same as being a number and either-a-number-or-blue, nor is it the same as being a number and either-blue-ornot-blue (recall our earlier discussion of "grue" and "bleen"). We reject that mutual necessitation suffices for generic identity, evading seemingly false consequences that (15)-(16) would have if fed through PARTIAL-GENERIC-ESSENCE: that being a number is essentially linked to being blue. ${ }^{15}$

PARTIAL-GENERIC-ESSENCE also looks extensionally adequate in cases where being $F$ is a genus (i.e. being an animal), with being $G$ a species of that genus (i.e. being human). In these cases, a differentia of the genus (i.e. being rational) serves as the 'supplementary' $H$ in PARTIAL-GENERIC-ESSENCE, and genus and differentia turn out essential to the species, as desired. But other cases may raise doubts. For instance, if having a mass is part of what it is to be an apple, it's hard to see which supplementary $H$ could be such that to be an apple is to have a mass and to be $H$.

Though this objection is natural, we can offer a remarkably simple proof that the biconditional corresponding to PARTIAL-GENERIC-ESSENCE is correct. Let " $F X \subseteq_{X} G x^{\prime}$ abbreviate "Being $F$ is part of what it is to be $G$ " (to preview notation introduced later). The proof relies on the following general principles about generic identity, partial generic essence, and their interaction:

\footnotetext{
14 Rayo is well aware of this (2013, p. 122). But like we said in fn. 8, certain contentious theses serve as backdrop for his discussion that we cannot evaluate here (but cf. Rayo 2016, pp. 17-21 for further discussion of his views on essence, which differs somewhat from his 2013).

15 The account of grounding that emerges in section 3 provides a further way to argue that our account evades these consequences of Rayo's account: see the end of section 4.
} 
(i) $\equiv_{x}$ is symmetric

(ii) $F X \equiv_{X} F X \wedge F X$

idempotence of $\wedge$

(iii) $\quad F X \subseteq_{X} G x \wedge F X$

$\wedge$-intro I

(iv) $F X \subseteq_{X} F X \wedge G X$

$\wedge$-intro II

(v) If $F x \subseteq_{x} G x$, then $F x \wedge H x \subseteq_{x} G x \wedge H x$

$\wedge$-adjunction for $\subseteq$

(vi) If $F x \subseteq_{x} G x$ and $G x \equiv_{x} H x$, then $F x \subseteq_{x} H x$

substitution

(vii) If $F X \subseteq_{X} G x$, and $G X \subseteq_{X} F X$, then $F X \equiv_{X} G X$

antisymmetry

And here's the proof:

Left-to-right. Suppose $F_{X} \subseteq_{X} G x$. Then by (v), $F x \wedge G X \subseteq_{x} G X \wedge G x$. By (i), (ii) and (vi), it follows that $F x \wedge G x \subseteq_{x} G x$. From this, plus (iii) and (vii), infer that $G x \equiv_{X} F x \wedge G x$. Hence, for some $H, G X \equiv_{X} F x \wedge H x$.

Right-to-left. Suppose for a given $H$ that $G x \equiv_{x} F x \wedge H x$. Then by (i), it follows that $F x \wedge H x \equiv_{x} G x$. By (iv) and (vi), infer $F x \subseteq_{x} G x$.

The proof is remarkable in its simplicity, but also (we take it) by the plausibility of the principles it assumes. (i) and (ii) are compulsory principles about generic identity, and counterparts of principles about factual identity advocated earlier. (iii)-(v) are analytic-sounding principles about partial generic essence. (vi) is an instance of Leibniz's Law for $\equiv$ (see section 1). We assume in effect that the context " $F X \subseteq_{X} \ldots$... is transparent for generic identity (surely, for instance, if being an animal is part of what it is to be a human being, then given that to be a human being is to be a Homo sapiens, being an animal is part of what it is to be a Homo sapiens). And (vii) looks compelling provided that "partial" in "partial essence" is understood in the liberal sense discussed before.

The above reasoning also gives a direct reply to the objection put forward above. The objection was that there appears to be no $H$ such that to be an apple is to have a mass and to have $H$ (although of course the worry generalizes). The left-to-right direction of the proof above provides us with such a feature: being an apple. The 
objection initially looked compelling, we think, due to assuming that $H$ must be proper conjunctive part of being an apple. As should be plain at this point, no such reading of PARTIAL-GENERIC-ESSENCE is intended. ${ }^{16}$

But what of the intimate link widely thought to hold between essence and 'real definition'? Our account entails that partial generic essence is reflexive (since for a thing to be $F$ is for it to be $F \wedge F$ by (ii) from the proof above), and that full generic essence is reflexive and symmetric (since $\equiv_{x}$ is reflexive and symmetric). On one hand, these consequences seem undeniable. If anything is essential to being human, it is being human; and we find it hard to fathom why being human would fail to be what it is to be a rational animal, if one accepts the reverse. On the other hand, one might complain that essentialist statements no longer supply real definitions, since real definitions - at least given a traditional conception that models them after reductive analyses - cannot be circular in either way.

There are in fact two objections to consider: one turns on a merely verbal matter, while the other is substantive. But first of all, what is a real definition? We adopt the more or less standard view that takes it to be a truth of a certain sort, one that-in the case of (13) - characterizes not what the word "human" happens to mean in English (which is the purview of a nominal definition), but rather what being a human is 'in itself' (see e.g. Fine 1994; Kment 2014, pp. 158-9; Koslicki 2012, pp. 190, 197-201; Lowe 2012, pp. 104-5; Rosen 2010, p. 122; 2015). On our view, only some true "To be $F$ is ..." statements express real definitions. And distinguishing those that $d o$ arguably only requires appealing to notions that are analyzable in terms of generalized identity, or that are plainly not essentialist (e.g. the truth-functional connectives). Since real definitions are expressed by a proper subset of true essentialist statements, we handle the more substantive challenge: to link essence and real definition in an intimate way. ${ }^{17}$ But suppose one insists on

\footnotetext{
16 To be clear: we are not denying that conjunctive parthood obeys something like the classical mereological principle of weak supplementation (thanks to a referee for pressing us to clarify here). Rather, what we say here is that it is hard to see what the supplemental conjunctive part would be in cases like the one at hand, which is of course compatible with there in fact being one. Whether conjunctive parthood obeys this (or some other) supplementation principle is a substantive question that we hope to address in future work.

17 We're not denying that philosophers can (and do) communicate real definitions using statements making no explicit mention of essence (e.g. necessitated universal biconditionals), nor that
} 
a more intimate link: i.e. that every truth of essence must express a real definition, if only a partial one. We demur, but the 'dispute' here strikes us as merely verbal. Those who insist on using "real definition" in this fashion could read our account as implicitly defining the notion of proto-essence, and then let us analyze (what they call) the notion of essence in a fashion exactly analogous to what we suggest below.

Now, there is no consensus-and considerable imprecision-about what kind of truth a real definition is, and specifically over whether a 'reductive analysis' type model is the only viable one (e.g. Rosen argues that recursive definitions can be real definitions: 2015, pp. 196-7). We certainly don't wish to take a stance on the matter here. Nor will we attempt to survey how our account stacks up to certain more precise proposals in the literature (though we hope to do so in the future). Our goal here is modest: to challenge the impression that there is some obstacle in principle, and on the assumption that real definitions must be non-circular.

Start with merely partial real definition and let (12) be our stock example. If our account is correct, the truth of (12) requires that being human is a conjunctive part of being Socrates. One obvious way to go is to further require of (12) that being Socrates isn't itself a conjunctive part of being human. Since conjunctive parthood is antisymmetric, this amounts to requiring that being Socrates and being human not be generically identical-and they clearly aren't. More generally, requiring that conjunctive parthood hold asymmetrically in a case of merely partial real definition gives substance to the idea that the definiens cannot itself be "built up' from the definiendum; and to the idea that the latter cannot be a part of the essence of the former, given that not being a conjunctive part of such-and-such entails not being part of its essence. (An even more demanding condition along these lines uses the notion of disjunctive parthood that we analyze in terms of gen-

philosophers use "real definition" to refer to whatever the definiens phrase contributes to the truth of the relevant sort of essentialist statement, rather than to the truth as a whole. The conditions we consider for an essentialist statement to express (what we call) a real definition can be tweaked in obvious ways to comport with these broader uses of the phrase. 
eralized identity in section 3 , and requires that the definiendum be neither a conjunctive part, nor a disjunctive part, nor either a conjunctive or disjunctive part of any conjunctive or disjunctive part, or ... of the definiens).

Full real definition-let (13) be the stock example-requires separate treatment. The first option will not do, of course, since (13) is a generic identity, and thus being human is a conjunctive part of being a rational animal and vice versa. Nor can we say that (13) expresses a real definition only if being human is grounded in being a rational animal, given the standard assumption that nothing grounds itself. This observation has led some to doubt that generic identity could be used to state what a full real definition is, given that the latter has a built-in priorityindicating directionality (cf. Cameron 2014, pp. 429; Fine 2015, pp. 308). But even if the two notions should not be identified (which we readily concede), it may well be that the second can be analyzed partially in terms of the first, perhaps with the aid of further non-essentialist notions.

One approach - a fairly traditional one-stems from the thought that a "To be $F$ is to be $G^{\prime \prime}$ statement expresses a real definition only if it takes a certain form. At minimum, the definiendum phrase must be different from the one expressing the definiens; but since this would not rule out pathological cases like "To be $F$ is to be both $F$ and $F^{\prime \prime}$, more must be said. Often, further constraints are placed on the constituent expressions from which the definiens expression is built. We cannot appraise every such constraint that has been suggested here (see e.g. King 1998 and Koslicki 2012 for just a couple). But one can imagine various constraints of this sort that are amenable to our account. One is to require that whatever is expressed by some proper constituent of the definiens phrase not have what is expressed by the definiendum phrase as a conjunctive part. Not only does (13) seem to meet this test, but as before this proposal gives substance to idea that the definiens cannot itself be 'built up' from the definiendum, and that the latter cannot be part of the essence of the former. (Although again, perhaps the more demanding condition we mentioned before is preferable.)

In floating these tentative proposals about how to sift out essentialist statements that express real definitions from those that do not, let us be clear: we have not 
surveyed whether they comport with all the nebulous ways "real definition" gets used in philosophical parlance, and there are no doubt other viable proposals to explore than the two offered.18 What we have shown is that our critic must explain why these proposals (or some extension thereof) are not up to the task.

If one agrees that the account of essence we've offered is extensionally adequate, one might finally wonder whether it is suitably 'reductive'. The case is mixed. On one hand, some who partake in "To be $F$ is ..." talk are skeptical of broadly Aristotelian notions of essence (cf. Rayo 2013, p. 5; 2015a). On the other, others attempting to communicate the relevant notions of essence treat "To be $F$ is ..." talk as a representative form of expression. Our own opinions diverge on the issue; but the important point is that even a non-reductive approach is faithful to our aims. Ideological economy is preserved, as we ultimately analyze grounding with "To be $F$ is ..." talk: if such talk is essentialist, one still trades two primitive ideological kinds (grounding and essence) for one. And even then, analyzing grounding in terms of such talk is a noteworthy way to unify the two indeed. So let's set aside whether such talk is essentialist, and turn to the fruits of unification we can gain from it.

\section{Grounding in terms of generalized identity}

Philosophers traditionally speak of grounding when they say that such-and-such in some sense 'makes' or 'brings about' so-and-so, in a constitutive rather than a causal sense that is unanalyzable in purely modal terms (see e.g. Bliss \& Trogdon 2014 for a general overview). Begin with factual grounding, as it's more familiar (generic grounding, which is less familiar, is left for later). We express the notion with statements like

Its being the case that $p_{1}, p_{2}, \ldots$ makes it the case that $q$;

we write them with Fine's (2012) familiar '<' symbol for strict full grounding as:

$$
p_{1}, p_{2}, \ldots<q
$$

\footnotetext{
${ }^{18}$ Correia (forthcoming) and Skiles (2014, pp. 225-230) sketch accounts of full real definition on the model of reductive analysis utilizing notions of grounding.
} 
For sake of ease, we will often speak in 'predicationalist' terms as if grounding were a relation between facts referred to by these Greek letters, but merely as shorthand for the 'operationalist' reading above (cf. Correia 2010, pp. 253-254).

We analyzed partial essence, recall, in terms of conjunctive parthood, which was defined in terms of generalized identity. We now propose to analyze grounding in terms of another parthood relation-disjunctive parthood-which we analyze in an analogous fashion, invoking disjunction instead of conjunction. Say that $p$ is a disjunctive part of $q$ (in symbols: $p \sqsubseteq^{\vee} q$ ) iff: for some $r$, for $q$ to hold is for $p \vee r$ to hold. (So, for instance, the ball's being red is a disjunctive part of its being eitherred-or-round.) Strictly speaking, we analyze grounding in terms of disjunctive parthood, together with a 'hybrid' notion which is itself defined in terms of disjunctive parthood. Say that $p$ is a conjunctive part of a disjunctive part of $q$ (in symbols: $p \sqsubseteq^{\wedge \vee} q$ ) iff: there's some $r$ such that $p \wedge r \sqsubseteq^{\vee} q$. (So, for instance, the ball's being red stands in this hybrid relation to being either both-red-and-round or blue.)

We claim that a collection of facts $p_{1}, p_{2}, \ldots$ grounds another fact $q$ iff conjoining $p_{1}$ $p_{2}, \ldots$ gives you a disjunctive part of $q$ (thus each of $p_{1}, p_{2}, \ldots$ is a conjunctive part of a disjunctive part of $q$ ), yet there's no way of conjoining facts with $q$ that gives you a disjunctive part of any of $p_{1}, p_{2}, \ldots$ (thus $q$ is not a conjunctive part of any disjunctive part of the facts in that collection). In symbols:

FACTUAL-GROUNDING $\quad p_{1}, p_{2}, \ldots<q$ iff: (i) $p_{1} \wedge p_{2} \wedge \ldots \underline{\complement}^{\vee} q$; and (ii) neither $q \sqsubseteq^{\wedge \vee} p_{1}$, nor $q \sqsubseteq^{\wedge \vee} p_{2}$, nor ...

A concrete example to illustrate: take the highly plausible claim that $a$ 's being red $\left(p_{1}\right)$ and $a$ 's being round $\left(p_{2}\right)$ jointly ground their conjunction $(q)$. Since for $q$ to hold is for $q \vee q$ to hold (by axiom A3 of the system GI from section 1), the first condition is met, as desired. And so long as $q$ is not itself a conjunctive part of a disjunctive part of either $p_{1}$ and $p_{2}$ in turn-an assumption that's eminently reasonable, but that we put on firmer footing shortly-the second condition is met. Hence, FACTUAL-GROUNDING gets the right result. 
It's not surprising that FACTUAL-GROUNDING handles this 'tailor-made' example. What's surprising is that there's good reason to believe it handles even the less obvious cases. But first, a couple clarifications.

First clarification: note that FACTUAL-GROUNDING employs the non-factive notion of generalized identity. Thus it characterizes a non-factive notion of grounding: it's not required that $p_{1}, p_{2}, \ldots$, and $q$ all hold for $p_{1}, p_{2}, \ldots$ to ground $q$ (cf. Fine 2012, pp. 48-50). A factive analogue can be wrought by adding a factivity condition: i.e., that $p_{1}, p_{2}, \ldots$ all hold. (We'll continue to work with the simpler non-factive account above, although the following discussion won't turn on it.)

Second clarification: given that generalized identity is symmetric and transitive, and that the rules R3 and R4 are truth-preserving, FACTUAL-GROUNDING entails that ground-theoretic status is preserved under factual identity. More precisely:

$$
\begin{aligned}
& a . \quad \text { If } p, p_{1}, p_{2} \ldots \text { ground } q \text { and } p \equiv p^{*} \text {, then } p^{*}, p_{1}, p_{2}, \ldots \text { ground } q \text {. } \\
& b \text {. If } p_{1}, p_{2}, \ldots \text { ground } q \text { and } q \equiv q^{*} \text {, then } p_{1}, p_{2}, \ldots \text { ground } q^{*} \text {. }
\end{aligned}
$$

FACTUAL-GROUNDING thus captures a worldly conception of grounding in the sense of Correia (2010, pp. 256-259) - albeit with the merely cosmetic difference that Correia there uses the term "factual equivalence", and the more substantive difference that we have adopted the successor logic of Correia (2016), i.e. the system GI. This substantially impacts how FACTUAL-GROUNDING should be understood, which is clearly visible in logical cases. $p$ is arguably factually identical to $p \vee p$, to $p \wedge p$, and to $\neg \neg p$, differing not in the way the world is represented as being, but rather how they represent the world as being that way (as Fine puts it: forthcoming, pp. 10-1). Yet if grounding is irreflexive, FACTUAL-GROUNDING entails that $p$ doesn't ground these 'other' facts. In contrast, a conception of grounding that's representational ("conceptual" is the term used in Correia 2010) requires that ground-theoretic status only be preserved under some more representation-sensitive notion of equivalence, which may distinguish $p$ from $p \vee p, p \wedge p$, and $\neg \neg p$. That FACTUAL-GROUNDING applies only to worldly grounding doesn't diminish its interest, we think, as the primary metaphysical interest in grounding concerns how 
it structures the world itself, independently of how we think or talk about it (cf. Correia 2010, pp. 258-9; Krämer \& Roski 2015, pp. 60-1).

Seen in this light, FACTUAL-GROUNDING is in a sense not completely new: the system for the logic of worldly grounding that Correia (2010) develops has a theoremhe calls it the Reduction Theorem - that is just a factivity-requiring analogue of the biconditional corresponding to FACTUAL-GROUNDING. Yet he isn't happy with this result. Correia worries that the first necessary condition imposed on grounding by FACTUAL-GROUNDING-embodied in what he calls the Reduction Axiom-entails that whatever is grounded "has a disjunctive nature", and that "grounding always arises via disjunction", which he takes to be implausible in general: "although one can maintain [...] that the fact that \{Socrates\} exists is grounded in the fact that Socrates exists, the view that the former fact is the disjunction of the latter fact and another fact is implausible" (ibid., p. 272).

There are a number of worries that could be lurking in the background here. And even setting those aside, to the extent one has intuitions about what is (and isn't) a 'disjunctive part' or a 'conjunctive part of a disjunctive part' of what, they're weak indeed; thus it's hard to see how to motivate our account. Let's change tack by taking an indirect route from grounding to generalized identity: by analyzing the first in terms of the second by means of a more intuitive notion we call $s u b$ sumption. By making use of subsumption-which many will find easier to grasp, and already plays a notable role in recent literature on grounding-we can more easily fend off worries with our account, and also provide reasons to accept it.

\subsection{The notion of subsumption}

Subsumption comes in a generic as well as in a factual variant-the latter will be used for factual grounding, and the former for a generic notion of grounding that we introduce later. Although generic grounding is less familiar, generic subsumption is intuitively easier to grasp and so we focus on it first.

To start with, consider a broader notion that subsumes (in the ordinary sense of the term) subsumption. Suppose that to be a human is be a rational animal. Then we take it that there's an intuitively natural sense in which one could then infer 
that being human is a way (or manner) of being an animal-a different way than, say, being a cat. This link between conjunctive parthood and "is a way of" talk is not incidental, as it readily generalizes beyond species-genus cases: one can say, for instance, that being Socrates is a way of being a human (if being human is a conjunctive part of being Socrates), that being red and round is a way of being red, and so on.

Importantly, this use of "is a way of" talk readily contrasts with causal readings of this idiom-expressed when one says, for instance, that traveling westward on the Hume Highway is a way of getting to Melbourne. Traveling westward on the Hume Highway could - in the metaphysical sense-have failed to be a way of getting to Melbourne, while being red and round could not-in this sense-have failed to be a way of being red.

We take any case of subsumption, like any case of conjunctive parthood, to be a case of being-a-way-of in the non-causal sense intended here. Instances of the determinate-determinable relation yield archetypical cases of subsumption: if being $F$ (e.g. being red) is a determinate of being $G$ (e.g. being colored), then we take $F$ to be subsumed by $G$, and (thus) take being $F$ to be a way for a thing to be $G$. Nonetheless, what holds for the determinate-determinable relation need not hold for subsumption more generally. First, a determinable property is always distinct from each determinate (by "distinct", we mean non-identical in the sense of generalized identity): being colored, e.g., is distinct from being red. Yet one should not take this as evidence that subsumption is irreflexive, since being $F$ (trivially) subsumes being $F$. Second, the determinates of a determinable property are typically many in number, and some of them may well be mutually incompatible: thus being red and being blue are both subsumed by being colored, and no single thing could be both. Yet, again, one should not take this as evidence that there will always be several incompatible ways subsumed by being so-and-so, provided that there is at least one. For instance, we take it that being Socrates is subsumed by being a member of \{Socrates\}, yet presumably there is no further, incompatible way of being a member of \{Socrates\} than being Socrates.

We also don't identify subsumption with being-a-way-of itself, as the former is 
systematically connected to grounding in ways that the latter isn't. It is natural, and standard, to assume that what serves as a ground must be wholly relevant (or contain no part that is irrelevant) to what it grounds (cf. Dasgupta 2014, pp. 4-5; Litland 2016, p. 534). This is not always the case for being- a-way-of: it is clear enough that being red and round is not wholly relevant to being red. Yet determinate-determinable connections satisfy this constraint: a thing's being red is not only a way of being colored, but also wholly relevant to being colored. As we understand it, "subsumption" stands for links of being-a-way-of that meet this relevance constraint.

What we said about generic subsumption we also want to say, mutatis mutandis, about the factual variety. Examples of link of factual subsumption are easily seen on a case-by-case basis (e.g. via the plausible thought that the ball's being either red or blue subsumes its being red), and thanks to the plausible principle that if being $G$ subsumes being $F$, then for any $x, x^{\prime}$ s being $G$ subsumes $x^{\prime}$ s being $F$.

For reasons that will soon become clear, we regiment statements of subsumption with Fine's (2012) " $\leq$ " notation for weak full grounding, and embellish it with a subscript when the statement is generic. Thus we write the generic subsumption statement "Being red is subsumed by being colored" as " $x$ is red $\leq_{x} X$ is colored" (and similarly for non-monadic cases), and write statements of factual subsumption of the form

Its being the case that $p$ is subsumed by its being the case that $q$

as

$p \leq q$.

\subsection{Grounding in terms of generalized identity via subsumption}

So what, exactly, is subsumption? And what bearing does it have on our account of what grounding is? To the first question, we will argue that subsumption is the converse of disjunctive parthood: such-and-such's being a wholly relevant way of being thus-and-so is nothing more than the former being a disjunctive part of the 
latter. And to the second question, we will argue that grounding can be analyzed in terms of subsumption in a manner exactly analogous to how we proposed to analyze grounding in terms of disjunctive parthood. Let's take these claims in reverse order, and as before focus on factual grounding (we will introduce and analyze the generic notion in due course).

We spoke earlier of conjunctive parts of a disjunctive part of such-and-such. In analogous way, it is natural to speak of conjunctive parts of what's subsumed by such-and-such. For example: given that being an animal is a conjunctive part of being a human, which is subsumed by being a living organism, being an animal bears this relation to being a living organism. Say that $p$ is quasi-subsumed by $q$ (in symbols: $p \lesssim q$ ) iff there is some $r$ such that $p \wedge r \leq q$. Replacing $\complement^{\vee}$ with $\leq$ in our original account of grounding, and $\complement^{\wedge \vee}$ with $\lesssim$, delivers the following subsumption-theoretic analogue:

$$
p_{1}, p_{2}, \ldots<q \text { iff: } \quad \text { (i) } p_{1} \wedge p_{2} \wedge \ldots \leq q \text {; and }
$$

(ii) neither $q \lesssim p_{1}$, nor $q \lesssim p_{2}$, nor $\ldots$

We are not the first to offer something akin to (i) as a requirement on factual grounding: Litland (2013, pp. 23-25) similarly takes $p_{1}, p_{2}, \ldots$ to ground $q$ only when $p_{1}, p_{2}, \ldots$ "collectively constitute a way for $[q]$ to be the case", and in that sense "[make] a difference to how $[q]$ obtains", and uses this condition to address putative counterexamples to the transitivity of grounding due to Schaffer (2012). The idea that (ii) is a further requirement can be supported as follows. Suppose for reductio that $p<q$, and yet $q \lesssim p$ (cases with several grounds can be treated in the same way). Then $q \wedge r \leq p$ for some given $r$, and therefore $q \wedge r<q$ (we here appeal to a plausible principle: if $s_{1} \leq s_{2}$ and $s_{2}<s_{3}$, then $s_{1}<s_{3}$ ). Which-we take it—could never be: conjunctions don't ground any of their conjuncts.

Moreover, there are striking similarities between (18) and principles defended in the literature that link grounding to notions in the vicinity of subsumption. For instance, when Fine (2012, pp. 51-54) introduces the weak full grounds of a fact, he characterizes them with a "For ... is for _." idiom that allows "_" to be plural, and that differ from the fact's strict full grounds as they "may also move us sideways in the explanatory hierarchy". With this notion, Fine tentatively proposes a 
definition of strict full grounding that is analogous to our (18):

$$
p_{1}, p_{2}, \ldots<_{\mathrm{KF}} q \text { iff } \quad \text { (i) } p_{1} \wedge p_{2} \wedge \ldots \leq_{\mathrm{KF}} q \text {; and }
$$

(ii) neither $q \S_{\mathrm{KF}} p_{1}$, nor $q \lesssim_{\mathrm{KF}} p_{2}$, nor $\ldots$,

where $<_{\mathrm{KF}}$ is used for strict full grounding, $\leq_{\mathrm{KF}}$ for weak full grounding, and $\S_{\mathrm{KF}}$ for weak partial grounding (where $p \S_{\mathrm{KF}} q$ iff there is some $p_{1}, p_{2}, \ldots, r$ such that $p, p_{1}$, $p_{2}, \ldots, r \lesssim_{\mathrm{KF}} q$ ). The analogy is inexact, since Fine's ground-theoretic notions are representational (he accepts that $p<_{\mathrm{KF}} p \wedge p$, and that it's never the case that $p$ $<_{\mathrm{KF}} p$ ), while our subsumption-theoretic notions are meant to be worldly (from which one can argue that that $p<p \wedge p$ never holds). ${ }^{19}$ Nonetheless, the analogy is apt: given difficulties with explicating what, exactly, Fine has in mind by weak grounding (cf. deRosset 2013), one could reasonably adopt our (18) as a way of explicating the worldly analogue of Fine's (19).

Litland (2013, pp. 23-25) also offers an analogue of (18), instead employing the notion of (metaphysical) explanation-how mentioned above (which he takes as primitive). Say that $p_{1}, p_{2}, \ldots$ are downward-subsumed by $q$ iff, as Litland phrases it, "any ways for $p_{1}, p_{2}, \ldots$ to obtain collectively constitute a way for $q$ to obtain". Litland's principle can then be formulated thus:

$$
\text { (20) } p_{1}, p_{2}, \ldots<_{\mathrm{JL}} q \text { iff }
$$

(i) $p_{1}, p_{2}, \ldots$ are downward-subsumed by $q$; and

(ii) there are no $r_{1}, r_{2}, \ldots$ such that $r_{1}, r_{2}, \ldots, q$ are downward-subsumed by some $p_{i}(i=1,2, \ldots)$

Though Litland has a representational notion of grounding in mind, suppose we treat (20) as concerning a worldly notion. Then the similarity to (18) isn't merely formal. For it's natural to take " $p_{1}, p_{2}, \ldots$ are downward-subsumed by $q$ " as equivalent to "for all $r_{1}, r_{2}, \ldots$ such that $r_{i}$ is subsumed by $p_{i}(i=1,2, \ldots), r_{1} \wedge r_{2} \wedge \ldots$ is subsumed by $q$ ". If so, then (20), together with plausible principles about subsumption, yields exactly the biconditional corresponding to our (18).

Thus we think this subsumption-theoretic account of grounding given by (18) is

${ }^{19}$ Take any $p$. By GI, $((p \wedge p) \wedge p) \equiv p$. Given that subsumption is reflexive (i.e. that for $p$ to hold is always a wholly relevant way for $p$ to hold) and the further principle that subsumption, if worldly, is closed under factual identity, $((p \wedge p) \wedge p) \leq p$ and so $(p \wedge p) \lesssim p$. So then by the irreversibility' condition (ii) of (18), $p<(p \wedge p)$ doesn't hold. 
worth taking seriously. So return now to the first question: what is subsumption? Our proposal is that it's simply the converse of disjunctive parthood. If so, then (18) delivers exactly the account of grounding in terms of disjunctive parthood that we started with. Moreover, one can motivate its extensional adequacy by reflecting on intuitions about what subsumes what (and what doesn't). Recall our example of $a$ 's being red $\left(p_{1}\right)$ and $a$ 's being round $\left(p_{2}\right)$, which ground their conjunction $(q)$. Earlier, we simply asserted that it is 'eminently reasonable' to say that $q$ is a conjunctive part of a disjunctive part of neither $p_{1}$ nor $p_{2}$, but now we can give it intuitively firmer backing: for $q$ and something else to hold isn't a wholly relevant way for $p_{1}$ to hold (since a part of $q$, namely $a$ 's being round, is intuitively irrelevant to $a$ 's being red), and similarly for $p_{2}$.

But why accept that subsumption is the converse of disjunctive parthood? Since disjunctions plausibly subsume their disjuncts, it seems safe to say that if $p$ is a disjunctive part of $q$, then $q$ subsumes $p$. But why accept the reverse? It turns out that a compelling proof for this biconditional can be given-one strikingly similar to the proof provided in section 2 that partial essence is coextensive with conjunctive parthood. It relies on general principles about factual identity, subsumption, and their interaction which are structurally analogous to those used in the earlier proof and just as plausible:

(i) $\quad \equiv$ is symmetric

(ii) $\quad p \equiv p \vee p$ idempotence of $\mathrm{V}$

(iii) $\quad p \leq q \vee p$ V-intro I

(iv) $\quad p \leq p \vee q$ V-intro II

(v) If $p \leq q$, then $p \vee r \leq q \vee r$ V-adjunction for $\leq$

(vi) If $p \leq q$ and $q \equiv r$, then $p \leq r$ substitution

(vii) If $p \leq q$ and $q \leq p$, then $p \equiv q$ antisymmetry

And here's the proof: 
Left-to-right. Suppose $p \leq q$. Then by (v), $p \vee q \leq q \vee q$. By (i), (ii), and (vi), it follows that $p \vee q \leq q$. From this, plus (iii) and (vii), it follows that $q \equiv p \vee q$. Hence, there is some $r$ such that $q \equiv p \vee r$.

Right-to-left. Suppose that $q \equiv p \vee r$ for some $r$. Then by (i), it follows that $p \vee r \equiv q$. Hence by (iv) and (vi), it follows that $p \leq q$.

Along with proving that $p$ is a disjunctive part of $q$ iff $q$ subsumes $p$ (which is good, albeit defeasible, reason to believe the one is the other), as with the earlier proof, the left-to-right direction of the present one helps dispel worries with the account of grounding we gave directly in terms of generalized identity earlier.

Correia's (2010) worry that his Reduction Axiom-which records the first necessary condition imposed upon grounding by FACTUAL-GROUNDING-entails that if a fact $p$ grounds a fact $q$, then $q$ is the disjunction of $p$ and another fact $r$, while, on the face of it, many grounded facts aren't disjunctive in that way. Yet the left-toright direction of the proof above provides us with such a fact: the improper disjunctive part of $q$, namely $q$ itself. Thus, the worry turns out to be unfounded.

Similar comments apply to an objection about how we handle what Fine (2015) calls generic grounding. We have in mind the notion expressed when one says that some things being such-and-such a way makes them be such-and-such other way, understood non-factively (e.g. when it's said that a thing's being red makes it be colored, without implying that anything is in fact red). Adding subscripts to Fine's " $<$ " notation, we formalize monadic statements of this type as follows:

$$
F_{1 X}, F_{2} X, \ldots<_{X} G X
$$

Defining generic analogues of $\complement^{\vee}$ and $\complement^{\wedge \vee}$, generic grounding is accounted for in a manner exactly analogous to FACTUAL-GROUNDING:

GENERIC-GROUNDING $\quad F_{1} X, F_{2} X, \ldots<_{X} G x$ iff: (i) $F_{1} X \wedge F_{2} X \wedge \ldots \sqsubseteq_{x}^{\vee} G x$; and (ii) neither $G x \sqsubseteq_{x}^{\wedge \vee} F_{1} x$, nor $G x \sqsubseteq_{x}^{\wedge \vee} F_{2} X, \ldots$

Disjunctive properties have a bad reputation in metaphysical circles. And though we deny that GENERIC-GROUNDING requires the existence of properties, one might 
worry that it renders what's generically grounded disjunctive in some extended, equally problematic sense. Suppose, for instance, that a thing's being in a certain neurophysiological state makes it be conscious. Given GENERIC-GROUNDING, to be conscious is to be either in that neurophysiological state or conscious. So then, one might worry, as with the notoriously disjunctive property being grue, things no longer genuinely resemble as a matter of their being conscious-from which one might infer that being conscious cannot be causally efficacious, figure into lawful generalizations or inductively confirmable hypotheses, and so on.

Set aside whether disjunctivity deserves this bad metaphysical reputation, which some have challenged (cf. Antony 2003, Clapp 2001, and Skiles 2016). Even so, having a disjunctive part alone cannot suffice for disjunctivity of this allegedly problematic sort. For any $F$ you like, a thing's being either $F$ or $F$ is no different than its being $F$ (what else could it be?); thus the criterion would overgeneralize. And indeed, if things do genuinely resemble as a matter of their being conscious, then having a proper disjunctive part cannot suffice for problematic disjunctivity either. Even if being in the relevant neurophysiological state is a disjunctive part of being conscious-and even if being in the relevant state is itself problematically disjunctive-it remains the case that conscious things in this state (trivially) genuinely resemble conscious things that aren't: namely, as a matter of their all being conscious. The worry initially looks compelling, we think, due to assuming that being conscious must be 'built up' from being in this state and some further proper disjunctive part that bestow no genuine resemblances between them. But no such understanding of disjunctive parthood is intended. ${ }^{20}$

Now there is a sense in which, given the account of essence developed in section 2 , what is grounded has a 'disjunctive nature': if $p_{1}, p_{2}, \ldots$ grounds $q$, then it's essential to $q$ 's holding that $\left(p_{1} \wedge p_{2} \wedge \ldots\right) \vee q$ holds. Yet many find it objectionable for a fact's grounds to figure into its essence in general. As Fine puts it, even if Socrates's being a philosopher grounds that there are philosophers, the grounded

20 What we say here is compatible with the view that disjunctive parthood obeys weak supplementation. The question whether the view should be countenanced is, like the corresponding question about conjunctive parthood (see fn. 16), substantive, and we hope to address it elsewhere. 
fact's essence still "knows nothing of Socrates"; and if the ball's being red grounds its being colored, the grounded fact's essence still "knows nothing of the specific colors" (2012, pp. 74-75; cf. Rosen 2010, pp. 130-133). But we see no way to make this worry precise that we find troublesome. One can represent that there are philosophers in thought or talk without reference to Socrates, since (as we stressed before) generalized identity is compatible with representational non-equivalence. And indeed, we find it at least as intuitive to say that $p_{1}, p_{2}, \ldots$ do figure into the essence of $q$, if their conjunction is subsumed by $q$ as we've claimed. If such-andsuch are all wholly relevant ways for the ball to be colored, that hardly seems incidental to this particular fact.

Another, related objection goes as follows. ${ }^{21}$ Call "C" the claim that Socrates's being a philosopher grounds that there are philosophers. Our account and $\mathrm{C}$, the objection starts, together entail that the fact $f$ that there are philosophers is identical to the fact $g$ that Socrates is a philosopher or there are philosophers. Yet this is incompatible with the view-call it "V" - that the existence of $f$ does not, while the existence of $g$ does, necessitate the existence of Socrates. Therefore, our account, together with $\mathrm{C}$, precludes V. But surely, an account of grounding should remain neutral with respect to $\mathrm{V}$, even in the presence of $\mathrm{C}$. Hence, the objection concludes, our account should be rejected. We deny that our account and $\mathrm{C}$ together entail that there are facts, and accordingly we would reject the very first step of the objection. But let us charitably assume that facts $f$ and $g$ do exist. Then we favor different responses. We have all along remained neutral on the question whether generalized identities yield objectual identities when the corresponding entities (facts, properties) are available (see fn. 3). One of us denies that they do, and rejects the first step of the objection. The other believes that they do, and rejects the neutrality requirement formulated at the end of the objection. ${ }^{22}$ We believe the neutrality requirement is not at all obvious once we remember that the issue here

\footnotetext{
21 Thanks to a referee for raising this concern.

22 Note that, interestingly, rejecting $\mathrm{V}$ doesn't require holding the view that everything $(f, g$ and Socrates, in particular) exists necessarily: one may adopt the view that (i) Socrates is a contingent existent, (ii) the fact $h$ that Socrates is a philosopher exists at a world iff Socrates exists (and perhaps: is a philosopher) at that world, and (iii) $g$ has disjunctive existence conditions, existing at a world iff either $f$ or $h$ exists at that world.
} 
is the existence conditions of facts conceived of as worldly 'chunks of reality' (whatever those might be; we're playing along for the sake of argument), not facts conceived of as propositions. Nothing (as far as we can see) prevents one from saying that the proposition that Socrates is a philosopher or there are philosophers requires the existence of Socrates, whereas the worldly 'chunk of reality'this proposition reports upon doesn't. Blurring the two issues together might be why the objection sounds compelling at first. ${ }^{23}$

Having now motivated our accounts of grounding and essence individually, what can reasoning with their common ideological core-generalized identity-tell us about how they interact? We consider this question in the remainder.

\section{Fine on unifying grounding and essence}

Fine (2015) intends, like us, to unify essence with grounding. Our two accounts aren't in direct competition, as his target notions aren't the same as ours: ours are worldly, while his are representational. ${ }^{24}$ Yet comparing the two allows us to highlight several attractive features of our own account vis-à-vis Fine's.

Fine's account presents a significant departure from his older views on essence and grounding: while he used to focus on the former in the objectual sense (as in e.g. his 1994) and on the latter in the factual sense (as in e.g. his 2012), he now acknowledges - like Correia (2006) — the generic dimension of essence, and-like us-that essence and grounding can be either generic or factual. His generic notions of these are expressed, respectively, as:

(21) It's essential to $x, y, \ldots$ being such that $q_{1}, q_{2}, \ldots$ that they be such that $p$ (in symbols: $p \leftarrow x, y, \ldots q_{1}, q_{2}, \ldots$ )

(22) Some things $x, y, \ldots$ being such that $p_{1}, p_{2}, \ldots$ makes them be such that that $q$ (in symbols: $p_{1}, p_{2}, \ldots \rightarrow x, y, \ldots q$ )

His factual notions can be expressed as follows:

23 See Mulligan and Correia (2013, section 2) for a survey of views that distinguish facts from true propositions and that allow for facts to have disjunctive existence conditions.

24 Evidence is given by the fact that Fine holds that the notion of essence he is concentrating on is irreflexive (2015, pp. 296-297) and that $p$ is essential to $p \wedge p$ (ibid., p. 308). 
(23) It's essential to its being the case that $q_{1}, q_{2}, \ldots$ that it be the case that $p$ (in symbols: $p \leftarrow q_{1}, q_{2}, \ldots$ )

(24) Its being the case that $p_{1}, p_{2}, \ldots$ makes it be the case that $q$ (in symbols: $\left.p_{1}, p_{2}, \ldots \rightarrow q\right)$

The structure of Fine's statements of ground mirrors that of the statements of ground we're interested in: one or more items ground a given item. In contrast, Fine's statements of essence may involve several items said to be (collectively) essentially such-and-such, whereas the statements of essence we focused on are one-one. Fine's essentialist notions are also 'strict', i.e. irreflexive or non-circular: an item cannot be essential to itself, or to a plurality of items which comprises it.

Yet the appearance of a conflict here is illusory. For we can express the kinds of essentialist statements Fine puts forward, and account for them in a way perfectly dual to our account of grounding. Use " $p \subset_{x, y}, \ldots q_{1}, q_{2}, \ldots$ " for "It's essential to $x, y$, ... being such that $q_{1}, q_{2}, \ldots$ that $p$ ", and use " $p \subset q_{1}, q_{2}, \ldots$ " for "It's essential to its being the case that $q_{1}, q_{2}, \ldots$ that it be the case that $p$ ", both understood as worldly and 'strict'. Define a notion of quasi partial essence $\subseteq$ as follows:

(25) $p \curvearrowleft_{\mathrm{v}} q$ iff: $p \vee r \subseteq_{\mathrm{v}} q$ for some $r$.

In other words, $p \Im_{\mathrm{v}} q$ holds just when $p$ is a disjunctive part of something that is essential to $q$. Then we can account for $\subset$-statements as follows:

(26) $p \subset_{\mathbf{v}} q_{1}, q_{2}, \ldots$ iff:

(i) $p \subseteq_{\mathrm{v}} q_{1} \wedge q_{2} \wedge \ldots$, and

(ii) neither $q_{1} \curvearrowleft_{\mathbf{v}} p$, nor $q_{2} \curvearrowleft_{\mathbf{v}} p$, nor $\ldots$

(This is a non-factive notion; a factive notion can be defined in the obvious way.) Taking C-statements on board significantly improves our own account, for we then see a perfect parallelism between our accounts of grounding and essence, as illustrated in the following table (corresponding factive notions are left aside): 


\begin{tabular}{|c|c|c|}
\hline & Grounding & Essence \\
\hline $\begin{array}{c}\text { Weak } \\
\text { notion }\end{array}$ & $\begin{array}{c}\operatorname{SubSUMPTION}(\leq) \\
p_{\mathrm{v}} q \text { iff: } p \text { is a disjunctive } \operatorname{part}_{\mathbf{v}} \text { of } q\end{array}$ & $\begin{array}{c}\text { PARTIAL ESSENCE }(\subseteq) \\
p \subseteq_{\mathrm{v}} q \text { iff: } p \text { is a conjunctive part }{ }_{\mathrm{v}} \text { of } q\end{array}$ \\
\hline $\begin{array}{l}\text { Quasi weak } \\
\text { notion }\end{array}$ & $\begin{array}{c}\text { QUASI SUBSUMPTION }(\lesssim) \\
p \lesssim_{\mathbf{v}} q \text { iff: } p \wedge r \leq_{\mathbf{v}} q \text { for some } r\end{array}$ & $\begin{array}{l}\text { QUASI PARTIAL ESSENCE }(\cong) \\
p \subseteq_{\mathrm{v}} q \text { iff: } p \vee r \subseteq_{\mathrm{v}} q \text { for some } r\end{array}$ \\
\hline $\begin{array}{l}\text { Strict } \\
\text { notion }\end{array}$ & $\begin{array}{c}\text { STRICT GROUNDING }(<) \\
q_{1}, q_{2}, \ldots<\mathbf{v} p \text { iff: } \\
\text { (i) } q_{1} \wedge q_{2} \wedge \ldots \leq_{\mathbf{v}} p \text {, and } \\
\text { (ii) no } q_{i} \text { is such that } p \lesssim_{\mathbf{v}} q_{i}\end{array}$ & $\begin{array}{l}\text { STRICT PARTIAL ESSENCE }(\subset) \\
\quad p \subset_{\mathbf{v}} q_{1}, q_{2}, \ldots \text { iff: } \\
\text { (i) } p \subseteq_{\mathbf{v}} q_{1} \wedge q_{2} \wedge \ldots, \text { and } \\
\text { (ii) no } q_{i} \text { is such that } q_{i} \curvearrowleft_{\mathbf{v}} p\end{array}$ \\
\hline
\end{tabular}

Thus our account of grounding and essence is truly unified, for both-in their weak, quasi weak, and strict variants-are ultimately accounted for in terms of a single notion: generalized identity. It is also uniform, since the account of each ground-theoretic variant is dual to the account of the corresponding essentialist notion. Substituting conjunction for disjunction in the account of $p \leq_{\mathbf{v}} q$ yields the account of $p \subseteq_{\mathrm{v}} q$; substituting conjunction for disjunction and disjunction for conjunction in the account of $p \S_{\mathbf{v}} q$ yields the account of $p \nwarrow_{\mathbf{v}} q$; and substituting the converse of conjunctive parthood for disjunctive parthood and the converse of the relation being a disjunctive part of a conjunctive part for the relation being a conjunctive part of a disjunctive part in the account of $q_{1}, q_{2}, \ldots<\mathrm{v} p$ yields the account of $p \subset_{\mathbf{v}} q_{1}, q_{2}, \ldots$.

Fine (2015, p. 297) claims that his own account is unified and uniform. But we have our doubts. For Fine, essence and grounding are constitutive relations: $p$ 's being essential for $q_{1}, q_{2}, \ldots$ amounts to $p$ 's being what he calls a constitutively necessary condition for $q_{1}, q_{2}, \ldots$, whereas $p_{1}, p_{2}, \ldots$ 's grounding $q$ amounts to $p_{1}, p_{2}, \ldots$ 's being a constitutively sufficient condition for $q$ (ibid., p. 306). So whether a sufficiently deep unity and uniformity between grounding and essence is secured turns crucially on how, exactly, "constitutively necessary condition" and "constitutively sufficient condition" are to be understood.

We can see two options, but neither seems up to the task. One is that " $p$ is a constitutively necessary condition for $q$ " is to be understood as " $p$ is constitutive of $q$, and a necessary condition for $q$ ", and " $p$ is a constitutively sufficient condition for 
$q$ " as " $p$ is constitutive of $q$, and a sufficient condition for $q$ ". The problem, at least if "necessary condition" and "sufficient condition" are understood in the familiar modal fashion, is that unacceptable results follow. For instance, being a number $(F)$ is essential to being a number and blue-or-not-blue $(G)$. So, being $F$ is constitutive of being $G$. But since being $F$ necessarily implies being $G$, the view, understood modally, entails that being $F$ grounds being $G$ (and it doesn't).

Now, Fine acknowledges notions of necessary and sufficient conditions which aren't modal, and which are not converse to each other (ibid., pp. 306-7), and it may be thought that the view in question is instead to be read as invoking these. But now we are left with one problem, which also affects the modal view: how is this notion of being constitutive of to be understood? Absent a fuller story, the account seems incomplete.

The second option is to claim that "constitutively" in the phrases "constitutively necessary/sufficient condition" is intended to mark two kinds of non-modal condition-the constitutively-necessary kind vs. the constitutively-sufficient kindwhich differ in their modal import. But this option seems at least as problematic as the previous one. The previous option secured at least some form of unity in the account of essence and grounding, as both are analyzed in terms of a single notion: being constitutive of. Yet with the present option, it is not at all clear what unifies constitutively-necessary conditions with constitutively-sufficient ones in more than name only, or why these non-modal conditions have the modal import they allegedly do. Perhaps part of the explanation is that both are determinates of the same determinable: being a constitutive condition of. But again: how is this notion to be understood? Absent a fuller story, the account seems incomplete. Our account, in contrast, analyzes grounding and essence in terms of the same family of notions, which we backed up with a theory about these notions we take to be independently motivated by how we intuitively understand "For ... is for __" statements as they're used in philosophical settings.

Fine (ibid, p. 308) also claims that both constitutive relations are to be taken as primitive. Now of course, we have no basis for faulting Fine for this reason alone: we've assumed (for the purposes of this paper, at least) that generic and factual 
identity are not reductively analyzable either. Even so, working with this latter class of primitives has significant advantages over working with Fine's. We've mentioned a number of respects in which our account is appealing when applied to essence and grounding individually. Given that these depend crucially on the distinctive features of generalized identity, it at best is unclear how to replicate them within Fine's account-that is, absent an as-yet untold story about the nature and logic of constitutive relations. (Not that the nature and logic of generalized identity is completely transparent; but at least there are tight analogies with another, more familiar 'no-difference' notion to guide us, i.e. objectual identity.)

This becomes even more apparent when we use generalized identity to evaluate principles linking grounding and essence. For instance, Fine claims that if being $F$ grounds being $G$, then being $G$ "will not in general (and perhaps will never be)" part of what it is to be $F$; for otherwise, being $F$ would be constitutive of being $G$ and vice versa (ibid., pp. 306-7). But this explanation strikes us as incomplete. If being constitutively-necessary for and being constitutively-sufficient for are both primitive, why couldn't the two hold in opposite directions? In contrast, Fine's claim follows immediately from our framework. For suppose $F X<_{X} G X$. Then by our account of grounding, it's not the case that $G x \lesssim_{x} F x$. Suppose for reductio that $G x$ $\subset_{x} F x$. Then by our account of strict essence, $G x \subseteq_{x} F x$. By our account of partial essence, this means that $F x \equiv_{x} G x \wedge H x$ for some $H$. By axiom A3 of GI and the transitivity of $\equiv$, it follows that $F x \equiv_{X}(G x \wedge H x) \vee(G x \wedge H x)$. By our account of subsumption, it follows that $G x \wedge H x \leq_{x} F x$, which, by our definition of $\lesssim$, implies that $G x \lesssim_{x}$ $F x$. Contradiction.

The framework also affords us resources to respond to a worry with Fine's claim. It's plausible to think that being red grounds being colored, and that it is part of what it is to be red is to be colored. Although we accept the grounding claim, we reject the essentialist claim. But why does the essentialist claim seem correct? Here are two (compatible) hypotheses. First, if being red grounds being colored, a thing's being colored is in full its either being red or (otherwise) colored, and so is-unlike, say, its being either human or not human-relevantly necessitated by its being red. The idea that being colored is part of what it is to be red might simply 
be prompted by this separate fact.

Second, perhaps a generic essentialist falsehood about being red is being confused for an objectual essentialist truth about the property being red: i.e., that being a color is part of what it is to be this very property. Suppose this is so, and that a thing cannot be red without having this property. Then it follows that the thing has a property which is a color (or, to put it more naturally, that it has a color). Presumably, a thing's having a color just is its being colored; thus it follows that a thing cannot be red unless it's also colored. Given how subtle these distinctions between the objectual and generic can be, perhaps it shouldn't surprise us that one essentialist claim is confused for the other.

Here are two further examples of how generalized identity illuminates the unity of grounding and essence. First, consider the claim that grounding holds only if there is some 'underlying' truth about essence. ${ }^{25}$ Our account predicts at least one sense in which this is correct. Specifically, our account predicts that if being $F$ grounds being $G$, the fact that being $F$ necessitates being $G$ can be derived from what it is to be $G$. For if being $F$ grounds being $G$, our account implies that being $G$ just is being $F$ or $H$ for some given $H$, and which on our account gives the (or a) full essence of being $G$. It then follows that necessarily, a thing is $G$ iff it is $F$ or $H$, which entails by straightforward modal reasoning that necessarily, a thing is $F$ only if it's also $G$, as desired. ${ }^{26}$

Second, consider the claim that not every necessary entailment or equivalent of such-and-such is also essential to it. This is only true in some cases-but in which cases is it false? Our account allows appeal to ground-theoretic resources when addressing the question. Specifically, since (worldly) ground-theoretic status is preserved under generalized identity, our account entails that being $F$ is at least in part of what it is to be $G$, only if $F$ is ground-theoretically equivalent to being

\footnotetext{
${ }^{25}$ For discussion of principles of this type, see the articles cited in fn. 1.

${ }^{26}$ Some argue that what's grounded needn't be necessitated by what grounds it, but see Skiles (2013, ch. $4 ; 2015$, pp. 739-41) for an alternative identity-based proposal of grounding designed to be compatible with 'grounding contingentism'. Whether Skiles's proposal and the one defended in this paper should be viewed as competitors-or instead as characterizing two kinds of grounding under one ideological umbrella-is an interesting question, but for another time.
} 
both $F$ and $G$ (in the sense discussed in section 2). Yet this needn't always be the case if being $F$ is necessarily entailed by or equivalent to being $G$. To recall one of Fine's (1994) famous examples: being Socrates and such that there are infinitely many prime numbers is necessarily entailed by and equivalent to being Socrates, yet presumably the former is ground-theoretically linked to the arithmetic realm in ways that the latter isn't. Given our account, this provides reason to believe that the former isn't part of the essence of the latter either, as desired.

To be clear, we don't claim that Fine's account cannot be supplemented with an informative story of what constitutive relations are that performs as well in its intended domain. We do, however, think that these comparisons bring some of the attractive features of our account into stark relief.

\section{Looking forward}

We have argued that grounding and essence can both be accounted for in terms of identity-generalized identity—and explained why the resulting framework is attractive. But this is hardly the last word on the matter. At least two classes of questions emerge for further work.

One class concerns how generalized identity-and thus, on our view, grounding and essence-fit into our cognitive lives. Such questions include: can the account be extended to representational notions of grounding and essence? How does one come to know which statements of generalized identity hold? And why does grasping some of them bring at least some degree of explanatory understanding, while grasping others (e.g. "To be human is to be human") doesn't?

Another class of questions instead concerns how generalized identity—and thus, on our view, grounding and essence-fit into fundamental reality. These include: are generic and factual identity primitive notions, as we've assumed? What (if anything) grounds facts about what is generically/factually identical to what? And do these notions fall under the same ideological kind as objectual identity? We suspect that existing work on questions such as these, inside metaphysics proper and out, would prove highly useful for answering related questions about grounding and essence. Grounding, essence, and identity individually have been 
topics at the center of metaphysical inquiry for quite some time. A fuller understanding of how the three behave collectively should, we think, be at the center of metaphysical inquiry for some time to come. ${ }^{27}$

\section{References}

Anderson, Alan \& Nuel Belnap (1962), “Tautological Entailments”, Philosophical Studies, 13, pp. 9-24.

(1963), "First Degree Entailments", Mathematische Annalen, 149, pp. 302-319.

Angell, Richard (1977), “Three Systems of First Degree Entailment, Journal of Symbolic Logic, 42, p. 147.

(1989), "Deducibility, Entailment, and Analytic Containment", in Jean Norman \& Richard Sylvan (eds.), Directions in Relevant Logic, Dordrecht: Kluwer, pp. 119-143.

Antony, Louise (2003), “Who's Afraid of Disjunctive Properties?”, Philosophical Issues, 13, pp. 1-21.

Audi, Paul (2012), "Grounding: Toward a Theory of the In-Virtue-Of Relation", Journal of Philosophy, 109, pp. 685-711.

(2015), "Explanation and Explication", in Chris Daly (ed.), The Palgrave Handbook of Philosophical Methods, Basingstoke: Palgrave Macmillan, pp. 208-230.

Bliss, Ricki \& Kelly Trogdon (2014), "Metaphysical Grounding”, in Edward Zalta (ed.), The Stanford Encyclopedia of Philosophy (spring 2016 edition), URL = <http://plato.stanford.edu/archives/spr2016/entries/grounding/>

Cameron, Ross (2014), “On the Lack of Direction in Rayo's The Construction of Logical Space", Inquiry, 57, pp. 427-441.

\footnotetext{
${ }^{27}$ For their comments on ancestors of this article, we wish to thank Dominik Aeschbacher, Andrew Bailey, Riccardo Baratella, Sam Baron, Corrine Besson, Philipp Blum, Martina Botti, Claudio Calosi, Pablo Carnino, Rebecca Chan, Michael J. Clark, Christina Conroy, Paul Daniels, Louis deRosset, Cian Dorr, Jeremy Goodman, Dana Goswick, Vincent Grandjean, Ghislain Guigon, Miguel Hoeltje, Kathrin Koslicki, Olivier Massin, Anna-Sofia Maurin, Kris McDaniel, Neil Mehta, Robert Michels, Kevin Mulligan, Benjamin Neeser, Donnchadh O'Conaill, Bryan Pickel, Jan Plate, Mike Raven, Agustín Rayo, Henrik Rydéhn, Pierre Saint-Germier, Maria Scarpati, Jonathan Schaffer, Jonathan Simon, Robin Stenwall, Tuomas Tahko, Elanor Taylor, Naomi Thompson, Kelly Trogdon, Jan Walker, Jennifer Wang, Nathan Wildman, Tobias Wilsch, Justin Zylstra, several anonymous referees, and audiences in Ascona, Bergamo, Bern, Bucharest, Dresden, Geneva, Gothenburg, Helsinki, Istanbul (Koç), Leeds, London (King's College), Neuchâtel, Oslo, Oxford, and Sassari. This article was written while F.C. was funded through the Swiss National Science Foundation projects "Grounding - Metaphysics, Science, and Logic" (CRSII1-147685), "The Metaphysics of Time and its Occupants" (BSCGI0_157792), and "Essences, Identities and Individuals" (100012_159472), the University of Neuchâtel's module of the European Commission's HORIZON 2020 Marie Sklodowska-Curie European Training Network DIAPHORA (H2020-MSCA-ITN-2015-675415), while A.J.S. received funding as a Swiss NSF Advanced Postdoc.Mobility researcher in the project "Metaphysics as an Explanatory Discipline: Grounding, Essence, and Identity" (167721), and while both received funding through the Swiss NSF project "The Nature of Existence: Neglected Questions at the Foundations of Ontology" (10012_150289). We are grateful for their generous support.
} 
Carnino, Pablo (2015), "On the Reduction of Grounding to Essence", Studia Philosophica Estonica, 7, pp. 56-71.

Clapp, Lenny (2001), “Disjunctive Properties: Multiple Realizations”, Journal of Philosophy, 98, pp. 111-136.

Correia, Fabrice (2005), Existential Dependence and Cognate Notions, Munich: Philosophia Verlag.

(2006), “Generic Essence, Objectual Essence, and Modality”, Noûs, 40, pp. 753-767.

(2010), “Grounding and Truth-Functions”, Logique et Analyse, 53, pp. 271-296.

(2013) "Metaphysical Grounds and Essence", in Manuel Hoeltje, Benjamin Schnieder, \& Alex Steinberg (eds.), Varieties of Dependence, Munich: Philosophia Verlag, pp. 271-291. 122.

(2016), "On the Logic of Factual Equivalence”, Review of Symbolic Logic, 9, pp. 103-

(forthcoming), "Real Definitions", Philosophical Issues.

Correia, Fabrice \& Benjamin Schnieder (eds.) (2012), Metaphysical Grounding, Cambridge: Cambridge University Press.

Cowling, Sam (2013), “Ideological Parsimony”, Synthese, 190, pp. 889-908.

Dasgupta, Shamik (2014), “The Possibility of Physicalism”, Journal of Philosophy, 111, pp. 557-592.

(2015), "Inexpressible Ignorance", Philosophical Review, 124, pp. 441-480.

(2016), "Metaphysical Rationalism", Noûs, 50, pp. 379-418.

Dorr, Cian (2016), “To Be F is To Be G”, Philosophical Perspectives, 30, pp. 39-134.

Dunaway, Billy (2013), "Modal Quantification without Worlds", in Karen Bennett and Dean Zimmerman (eds.), Oxford Studies in Metaphysics, vol. 8, Oxford: Oxford University Press, pp. 151-186.

Eklund, Matti (2014), “Rayo’s Metametaphysics”, Inquiry, 57, pp. 483-497.

Fine, Kit (1994), “Essence and Modality”, Philosophical Perspectives, 8, pp. 1-16.

(2012), "Guide to Ground" in Correia and Schnieder (2012), pp. 37-80.

(2015), "Unified Foundations for Essence and Ground", Journal of the American Philosophical Association, 1, pp. 296-311.

(2016), “Angellic Content", Journal of Philosophical Logic, 45, pp. 199-226

(forthcoming), "A Theory of Truthmaker Content II: Subject Matter, Common Content, Remainder, and Ground", Journal of Philosophical Logic. 
Goodman, Nelson (1955), Fact, Fiction, and Forecast, Cambridge: Harvard Univ. Press.

Greco, Daniel (2015), “The Epistemology of 'Just is'-Statements”, Philosophical Studies, 172, pp. 2599-2607.

Greenberg, Mark (2014), "Troubles for Content II: Explaining Grounding”, in Alexis Burgess \& Brett Sherman (eds.), Metasemantics, Oxford: Oxford Univ. Press, pp. 169-184.

Guigon, Ghislain (forthcoming), "Truths qua Grounds”, Philosophy and Phenomenological Research.

Hofweber, Thomas (2014), "Rayo's The Construction of Logical Space", Inquiry, 57, pp. 442-454.

King, Jeffrey (1998), “What is a Philosophical Analysis?”, Philosophical Studies, 90, pp. 155-179.

Kment, Boris (2014), Modality and Explanatory Reasoning, Oxford: Oxford Univ. Press.

Koslicki, Kathrin (2012), "Varieties of Ontological Dependence", in Correia \& Schnieder (2012), pp. 186-213.

(2015), "The Coarse-Grainedness of Grounding", in Karen Bennett \& Dean Zimmerman (eds.), Oxford Studies in Metaphysics, 9, Oxford: Oxford Univ. Press, pp. 306349.

Krämer, Stephan and Stefan Roski (2015), "A Note on the Logic of Worldly Ground", Thought, 4, pp. 59-68.

Lewis, David (1986), On the Plurality of Worlds, Oxford: Blackwell.

Linnebo, Øystein (2014), “'Just is'-Statements as Generalized Identities”, Inquiry, 57, pp. 466-482.

Litland, Jon (2013), "On Some Counterexamples to the Transitivity of Grounding", Essays in Philosophy, 14, pp. 19-32.

(2016), "Pure Logic of Many-Many Ground", Journal of Philosophical Logic, 45, pp. 531-577.

Lowe, E. J. (2008), “Two Notions of Being: Entity and Essence”, Philosophy, 83, pp. 23-48.

(2009), "An Essentialist Approach to Truth-Making", in E. J. Lowe \& Adolf Rami (eds.), Truth and Truth-Making, Stocksfield: Acumen, pp. 201-216.

(2012), "What is the Source of Our Knowledge of Modal Truths?", Mind, 484, pp. 919-950.

Mulligan, Kevin \& Fabrice Correia (2013), "Facts", The Stanford Encyclopedia of Philosophy, $\mathrm{URL}=<$ http://plato.stanford.edu/entries/facts/>

Prior, Arthur (1971), Objects of Thought (eds. Peter Geach and Anthony Kenny), Oxford: Clarendon Press. 
Rayo, Agustín (2013), The Construction of Logical Space, Oxford: Oxford Univ. Press.

(2014), “Replies to Critics”, Inquiry, 57, pp. 498-534.

(2015a), "Essence Without Fundamentality”, Theoria, 30, pp. 349-363.

(2015b), "Replies to Greco and Turner", Philosophical Studies, 172, pp. 2617-2620.

Rayo, Agustín and Stephen Yablo, "Nominalism through De-Nominalization", Noûs, 35, pp. 74-92.

Robertson, Teresa and Philip Atkins (2016), "Essential vs. Accidental Properties", The Stanford Encyclopedia of Philosophy (summer 2016 edition), URL = <http://plato.stanford.edu/archives/sum2016/entries/essential-accidental/>

Rosen, Gideon (2010), "Metaphysical Dependence: Grounding and Reduction", in Bob Hale and Aviv Hoffman (eds.), Modality: Metaphysics, Logic, and Epistemology, Oxford: Oxford University Press, pp. 109-136.

(2015), “Real Definition”, Analytic Philosophy, 56, pp. 189-209.

Russell, Gillian (2014), "Hybrid Identities and Just Being Yourself”, Inquiry, 57, pp. 455465.

Schaffer, Jonathan (2012), "Grounding, Transitivity, and Contrastivity", in Correia and Schnieder (2012), pp. 122-138.

Shalkowski, Scott (2008), "Essence and Being”, Philosophy, 83, pp. 49-63.

Sider, Theodore (2014), "Outscoping and Discourse Threat", Inquiry, 57, pp. 413-426.

Skiles, Alexander (2013), Getting Grounded: Essays in the Metaphysics of Fundamentality, Ph.D. dissertation, University of Notre Dame.

(2014), "Primitivism about Intrinsicality", in Robert Francescotti (ed.), Companion to Intrinsic Properties, Berlin: De Gruyter, pp. 221-252.

(2015), “Against Grounding Necessitarianism”, Erkenntnis, 80, pp. 717-751.

(2016), “In Defense of the Disjunctive”, Inquiry, 59, pp. 471-487.

Trogdon, Kelly (2013), “Grounding: Necessary or Contingent?" Pacific Philosophical Quarterly, 94, pp. 465-485.

Turner, Jason (2015), "The Construction of Logical Space and the Structure of Facts", Philosophical Studies, 172, pp. 2609-2616.

Wedgwood, Ralph (2007), The Nature of Normativity, Oxford; Oxford University Press.

Williamson, Timothy (2003), "Everything”, Philosophical Perspectives, 17, pp. 415-465.

Wright, Crispin (2007), "Quantifying into Predicate Position: Steps Towards a New(tralist) Perspective", in Mary Leng, Alexander Paseau, and Michael Potter (eds.), Mathematical Knowledge, Oxford: Oxford University Press, pp. 150-174. 
Zylstra, Justin (forthcoming), "Essence with Ground", Analytic Philosophy. 